\title{
Correlation between Accelerometer and Questionnaire-Based Assessment of Physical Activity in Patients with Cerebral Palsy
}

\author{
Ki Bum Kwon, MD, Young Choi, MD*, Ki Hyuk Sung, MD, Chin Youb Chung, MD,
} Kyoung Min Lee, MD, Soon-Sun Kwon, $\mathrm{PhD}^{\dagger}$, Gyeong Hee Cho, PhD, Moon Seok Park, MD

\author{
Department of Orthopedic Surgery, Seoul National University Bundang Hospital, Seongnam, \\ ${ }^{*}$ Department of Orthopaedic Surgery, Kosin University Gospel Hospital, Busan, \\ ${ }^{\dagger}$ Department of Mathematics, College of Natural Sciences, Ajou University, Suwon, Korea
}

\begin{abstract}
Background: Precise measuring and monitoring of physical activity (PA) in patients with cerebral palsy (CP) are critical for assessing their PA participation and its potential health benefits. Accelerometer-based assessment of PA has been considered valid, reliable, and practical in children with CP. Therefore, we investigated the correlation between accelerometer- and questionnaire-based assessment of PA in CP patients.

Methods: Nineteen patients with CP who were classified as Gross Motor Function Classification System level I-III and 84 normally developed participants were included in the study. Study participants wore an accelerometer for seven days, after which they visited the hospital and completed the International Physical Activity Questionnaire (IPA0). CP patients and their caregivers completed the Pediatric Outcomes Data Collection Instrument (PODCI) and the Caregiver Priorities and Child Health Index of Life with Disabilities, respectively. The concurrent validity of the questionnaires was assessed.

Results: In the accelerometer-based assessment, time spent in PA was significantly shorter at every intensity level in CP patients than in normally developed participants. However, PA assessed by the IPAO was significantly higher in patients with $\mathrm{CP}$, indicating that they tend to exaggerate their participation in PA. On the correlation of the assessment by the accelerometer and by the PODCI, transfer/basic mobility, sports/physical function, and happiness increased significantly as the number of steps taken and the distance travelled increased.

Conclusions: In patients with CP, happiness and quality of life are associated with higher levels of PA. Thus, programs for patients with $\mathrm{CP}$ should focus on improving their PA.

Keywords: Cerebral palsy, Physical activity, Accelerometer, Questionnaires, Validity
\end{abstract}

Cerebral palsy $(\mathrm{CP})$ is a permanent disorder due to nonprogressive disturbances occurring in the developing fetal

Received June 10, 2019; Accepted July 23, 2019

Ki Bum Kwon and Young Choi contributed equally to this article as first authors.

Correspondence to: Ki Hyuk Sung, MD

Department of Orthopedic Surgery, Seoul National University Bundang

Hospital, 82 Gumi-ro 173beon-gil, Bundang-gu, Seongnam 13620, Korea

Tel: +82-31-787-7203, Fax: +82-31-787-4056

E-mail: skh1219@naver.com or immature infant brain. ${ }^{1)}$ Patients with $\mathrm{CP}$ have difficulties with movement and posture, which lead to activity limitations. Although CP is a nonprogressive disease, the risk of musculoskeletal problems increases and functional ability decreases with age. ${ }^{2)}$ Difficulties in independent movement and poor posture control due to decreased motor function in patients with $\mathrm{CP}$ might affect their participation in physical activities (PAs).

PA is defined as any bodily movement produced by skeletal muscles that results in energy expenditure. ${ }^{3)}$ It is one of the most basic human functions and engaging in 
Kwon et al. Physical Activity in Cerebral Palsy Patients

Clinics in Orthopedic Surgery • Vol. 12, No. 1, $2020 \bullet$ www.ecios.org

PAs lowers risks of diseases such as coronary artery disease, hypertension, diabetes, osteoporosis, and obesity. However, a delay in development of fundamental motor function may limit PA and can lead patients with $\mathrm{CP}$ to choose a more sedentary lifestyle to avoid movement difficulties. ${ }^{5}$ Limited engagement in PA may contribute to the development of the diseases mentioned above. ${ }^{6}$ Therefore, precise measuring and monitoring of PA in patients with $\mathrm{CP}$ are critical for assessing their participation in $\mathrm{PA}$ and its potential health benefits.

Given the increased need to measure PA, various objective and subjective assessment tools and questionnaires have been developed. Among the objective assessment tools, accelerometry-based monitors have been shown to provide a valid, reliable, and practical measure of PA in free-living conditions, ${ }^{7)}$ and previous studies have shown accelerometers to be valid and reliable in children with disabilities such as CP. ${ }^{8,9)}$ Subjective assessment tools refer to self-reported questionnaires, some of which are used worldwide. The International Physical Activity Questionnaire (IPAQ) was developed as the first international effort to provide a comparable self-report measure of PA and has been found to have reasonable reliability and validity. ${ }^{10,11)}$ In pediatric orthopedic surgery, the Pediatric Outcomes Data Collection Instrument (PODCI) was developed to assess musculoskeletal health outcomes in children and adolescents ${ }^{12)}$ and the Caregiver Priorities and Child Health Index of Life with Disabilities (CPCHILD) has been used to measure quality of life in patients with $\mathrm{CP}^{13,14)}$

In the present study, we aimed to evaluate PA in patients with $\mathrm{CP}$ by assessing the correlation between the accelerometer- and questionnaires-derived data and by comparing it with the PA of normally developed participants.

\section{METHODS}

We conducted this study in compliance with the principles of the Declaration of Helsinki. This prospective study was approved by the Institutional Review Board of Seoul National University Bundang Hospital (IRB No. B-1210/173009). Informed consent was obtained from all participants or their legal guardians. Nineteen ambulatory patients with CP who were classified as Gross Motor Function Classification System (GMFCS) levels I-III and 84 normally developed participants were included in the study. Normal participants consisted of healthy adults without $\mathrm{CP}$ or other neuromuscular diseases.

\section{Data Collection}

After being given instructions on how to wear and handle an accelerometer, all participants were asked to wear it throughout the day except during water-based activities such as bathing or swimming. Participants wore an accelerometer for 7 consecutive days. After the 7 days, all participants visited the hospital and completed the short and long versions of the IPAQ. Patients with CP completed the PODCI; their caregivers, the CPCHILD.

\section{Accelerometer (Fitbit One)}

Accelerometers operate by measuring acceleration along a given axis and then assessing the correlation between acceleration and PA. They provide real-time estimates of duration, frequency, and intensity of free-living PA. ${ }^{15}$ Accelerometers have an advantage over the pedometer, another objective measurement device of PA, because of their ability to distinguish between walking and running. Currently, accelerometers are considered one of the standard devices for assessing free-living PA levels and are often used to validate pedometers or PA questionnaires. ${ }^{16-18)}$ At least 7 days are required to obtain consistent measures of PA patterns. ${ }^{19)}$ In this study, participants were required to wear a Fitbit One (Fitbit Inc., San Francisco, CA, USA) triaxial accelerometer, which measures acceleration along three different axes. Participants were asked to wear the accelerometers on a belt for consistency.

\section{IPAQ}

The long version of the questionnaire consists of 25 questions assessing PA and two questions assessing sedentary behavior. The 25 questions are grouped into four domains: work activities, travel activities, household and yard-work activities, and recreational activities. The frequency and duration of PA are recorded as either vigorous or moderate in intensity within the domains of work activities, household and yard-work activities, and recreational activities. Walking is recorded and treated separately from the other activities. The short version of the IPAQ consists of six questions assessing PA and one question assessing sedentary behavior. The questions collect information on vigorous activity, moderate activity, and walking.

\section{PODCI}

The PODCI assesses musculoskeletal health outcomes in children and adolescents, and previous studies have reported that the PODCI reasonably reflects responsiveness to orthopedic treatment. ${ }^{20,21)}$ It is composed of six subscales: upper extremity/physical function, transfer/ basic mobility, sports/physical functioning, pain/comfort, 
happiness, and global functioning.

\section{CPCHILD}

The CPCHILD was developed to assess the health-related quality of life of children with severe developmental disabilities from the perspective of their caregivers. ${ }^{13)}$ It is composed of six domains: personal care/activities of daily living; positioning, transferring and mobility; comfort and emotions; communication and social interaction; health; and overall quality of life. A systematic review found the CPCHILD to be one of the strongest measures of quality of life in children with $\mathrm{CP}^{22)}$

\section{Statistical Methods}

Summary variables of minutes per week for different intensity levels of PA within each domain were calculated from the short and long versions of the IPAQ. Total minutes per week of vigorous activity, moderate activity, and walking were multiplied by 8,4 , and 3.3 , respectively, and then summed to create the total physical activity Meta-

\section{Table 1. Demographic Data of Participants}

\begin{tabular}{|ccc|}
\hline \multicolumn{1}{|c}{ Characteristic } & $\begin{array}{c}\text { Patients with } \\
\text { cerebral palsy }\end{array}$ & $\begin{array}{c}\text { Normal } \\
\text { participant }\end{array}$ \\
\hline Sex (male : female) & $15: 4$ & $27: 57$ \\
\hline Age (yr) & $19.7 \pm 6.0$ & $29.2 \pm 4.6$ \\
\hline Weight $(\mathrm{kg})$ & $58.4 \pm 11.7$ & $60.4 \pm 13.1$ \\
\hline Body mass index $\left(\mathrm{kg} / \mathrm{m}^{2}\right)$ & $21.2 \pm 3.4$ & $22.0 \pm 3.4$ \\
\hline GMFCS level $\mathrm{:} \| \mathrm{I}: \mathrm{ll}$ & $10: 3: 6$ & - \\
\hline
\end{tabular}

Values are presented as mean \pm standard deviation. GMFCS: gross motor function classification system. bolic Equivalent Task score. Summary variables for sedentary, lightly active, fairly active, and very active PA were also calculated from the data captured by accelerometers. PODCI and CPCHILD data were scored according to the guidelines provided by the questionnaires' manuals. The concurrent validity of the questionnaires compared with the accelerometer was assessed by using Spearman's rank correlation. All statistical analyses were performed using SPSS ver. 18.0 (SPSS Inc., Chicago, IL, USA) and p-values of $<0.05$ were considered statistically significant.

\section{RESULTS}

Nineteen patients with $\mathrm{CP}$ were included in this study with a control group of 84 normally developed participants. The mean age was $19.7 \pm 6$ years (range, 10 to 33 years) in patients with $\mathrm{CP}$ and $29.2 \pm 4.6$ years (range, 18 to 38 years) in normally developed participants. Ten of the patients (52.6\%) were classified as GMFCS level I; three (15.8\%), level II; and six (31.6\%), level III (Table 1).

The number of steps and the distance travelled were significantly lower in patients with CP $(p<0.001)$. Furthermore, according to the accelerometer-based assessment, time spent in PA was significantly shorter at every intensity level in patients with CP than in normally developed participants, whereas time spent being sedentary was significantly longer in patients with CP $(p<0.001)$ (Table $2)$. However, PA assessed by the IPAQ was significantly higher in the patients than in normally developed participants (Table 3).

For the PODCI, sports/physical activity $(p=0.035)$, happiness $(p=0.039)$, and global function $(p=0.005)$ decreased significantly with age for patients, while pain increased $(p=0.004)$. In addition, pain increased $(p=0.000)$

\section{Table 2. Physical Activity Assessed by an Accelerometer}

\begin{tabular}{|c|c|c|c|c|c|c|}
\hline \multirow{2}{*}{ Variable } & \multicolumn{4}{|c|}{ Patient with cerebral palsy } & \multirow{2}{*}{$\begin{array}{c}\text { Normal } \\
\text { participant }\end{array}$} & \multirow{2}{*}{$\begin{array}{c}p \text {-value } \\
\text { (total \& normal) }\end{array}$} \\
\hline & GMFCS level I & GMFCS level II & GMFCS level III & Total & & \\
\hline Step & $5,243 \pm 1,943$ & $4,436 \pm 1,452$ & $3,315 \pm 1,578$ & $4,506 \pm 1,894$ & $7,966 \pm 2,979$ & $<0.001$ \\
\hline Distance & $3.6 \pm 1.3$ & $3.1 \pm 1.0$ & $2.3 \pm 1.1$ & $3.1 \pm 1.3$ & $5.5 \pm 2.1$ & $<0.001$ \\
\hline Sedentary (min) & $1,360.5 \pm 77.1$ & $1,313.2 \pm 106.4$ & $1,367.4 \pm 33.0$ & $1,355.2 \pm 70.0$ & $1,249.1 \pm 108.5$ & $<0.001$ \\
\hline Lightly active (min) & $47.8 \pm 47.0$ & $82.7 \pm 78.8$ & $48.8 \pm 18.0$ & $53.9 \pm 45.3$ & $126.4 \pm 80.6$ & $<0.001$ \\
\hline Fairly active (min) & $25.6 \pm 26.0$ & $37.7 \pm 31.2$ & $18.9 \pm 13.3$ & $25.4 \pm 23.1$ & $50.8 \pm 29.1$ & 0.001 \\
\hline Very active (min) & $6.2 \pm 7.5$ & $6.4 \pm 6.2$ & $3.8 \pm 7.2$ & $5.5 \pm 6.9$ & $12.4 \pm 9.4$ & 0.003 \\
\hline
\end{tabular}

Values are presented as mean \pm standard deviation.

GMFCS: gross motor function classification system. 
and happiness decreased $(p=0.000)$ significantly as body mass index increased. Transfer/basic mobility, sports/ physical function, and happiness increased significantly as the number of steps and the distance travelled increased (Table 4). However, any subscales of PODCI were not significantly correlated with PA assessed by IPAQ.

\section{Table 3. Time Spent Being Active Assessed by IPAO}

\begin{tabular}{cccc} 
Total PA & Cerebral palsy & Normal & $p$-value \\
\hline Short-IPA0 & $933 \pm 995$ & $432 \pm 445$ & 0.001 \\
\hline Long-IPA0 & $2,126 \pm 3,299$ & $982 \pm 1,394$ & 0.019 \\
\hline
\end{tabular}

Values are presented as mean \pm standard deviation.

IPAO: International Physical Activity Questionnaire, PA: physical activity.
For the CPCHILD, overall quality of life decreased significantly with age $(p=0.002)$ and comfort/emotions increased $(p=0.045)$ with the number of steps taken. Positioning, transferring and mobility, and overall quality of life subscales were significantly different according to the GMFCS level ( $p=0.030$ and $p=0.043$, respectively) (Table $5)$.

\section{DISCUSSION}

This study has a limitation that needs to be addressed before the results can be discussed. Since the accelerometers were placed on a belt, they would not have captured upper extremity movement, possibly underestimating PA arising from wheelchair use. Patients classified as GMFCS level II or III may use a self-propelled wheelchair when travelling

\section{Table 4. Correlation between Pediatric Outcomes Data Collection Instrument and Accelerometric Data}

\begin{tabular}{lcccccc}
\multicolumn{1}{c}{ Variable } & $\begin{array}{c}\text { Upper extremity/ } \\
\text { physical function }\end{array}$ & $\begin{array}{c}\text { Transfer/ } \\
\text { basic mobility }\end{array}$ & $\begin{array}{c}\text { Sports/ } \\
\text { physical function }\end{array}$ & $\begin{array}{c}\text { Pain/ } \\
\text { comfort }\end{array}$ & Happiness & Global function \\
\hline Age & $-0.108(0.660)$ & $-0.389(0.099)$ & $-0.485(0.035)$ & $-0.626(0.004)$ & $-0.478(0.039)$ & $-0.618(0.005)$ \\
\hline Body mass index & $0.195(0.423)$ & $0.127(0.606)$ & $-0.199(0.413)$ & $-0.743(0.000)$ & $-0.743(0.000)$ & $-0.400(0.090)$ \\
\hline Accelerometer & & & & & & \\
\hline Step & $0.015(0.953)$ & $0.489(0.033)$ & $0.478(0.038)$ & $0.266(0.270)$ & $0.508(0.026)$ & $0.419(0.074)$ \\
\hline Distance & $0.004(0.986)$ & $0.498(0.031)$ & $0.504(0.028)$ & $0.281(0.244)$ & $0.511(0.025)$ & $0.435(0.063)$ \\
\hline Sedentary $(\min )$ & $0.172(0.481)$ & $-0.245(0.311)$ & $-0.208(0.394)$ & $-0.071(0.771)$ & $-0.164(0.501)$ & $-0.118(0.629)$ \\
\hline Lightly active $(\mathrm{min})$ & $-0.110(0.655)$ & $0.197(0.418)$ & $0.108(0.659)$ & $-0.016(0.950)$ & $0.081(0.742)$ & $0.040(0.872)$ \\
\hline Fairly active $(\mathrm{min})$ & $-0.248(0.307)$ & $0.300(0.212)$ & $0.283(0.240)$ & $0.126(0.606)$ & $0.183(0.453)$ & $0.170(0.487)$ \\
\hline Very active $(\mathrm{min})$ & $-0.193(0.428)$ & $0.195(0.425)$ & $0.443(0.057)$ & $0.391(0.098)$ & $0.514(0.024)$ & $0.366(0.124)$ \\
\hline
\end{tabular}

Values are presented as correlation coefficient $r$ ( $p$-value).

\section{Table 5. Summary of CPCHILD Questionnaire in Children with Cerebral Palsy}

\begin{tabular}{lccccccc} 
Variable & $\begin{array}{c}\text { Personal care/ } \\
\text { activities of daily } \\
\text { living }\end{array}$ & $\begin{array}{c}\text { Positioning, } \\
\text { transferring and } \\
\text { mobility }\end{array}$ & $\begin{array}{c}\text { Comfort and } \\
\text { emotion }\end{array}$ & $\begin{array}{c}\text { Communication } \\
\text { and social } \\
\text { interaction }\end{array}$ & Health & $\begin{array}{c}\text { Overall quality } \\
\text { of life }\end{array}$ & $\begin{array}{c}\text { Total score } \\
\text { GMFCS I }\end{array}$ \\
$90.9 \pm 15.6$ & $93.1 \pm 11.7$ & $92.2 \pm 9.8$ & $86.9 \pm 15.4$ & $67.0 \pm 30.6$ & $70.0 \pm 25.4$ & $90.0 \pm 9.3$ \\
\hline GMFCS II & $90.5 \pm 5.9$ & $84.0 \pm 11.9$ & $89.3 \pm 2.4$ & $72.1 \pm 17.1$ & $67.5 \pm 5.0$ & $40.0 \pm 16.3$ & $84.1 \pm 4.5$ \\
\hline GMFCS III & $86.9 \pm 23.3$ & $73.6 \pm 13.1$ & $75.8 \pm 27.3$ & $71.4 \pm 19.4$ & $68.0 \pm 11.0$ & $44.0 \pm 8.9$ & $76.9 \pm 10.6$ \\
\hline Total & $89.7 \pm 16.3$ & $86.0 \pm 14.2$ & $87.3 \pm 16.3$ & $79.7 \pm 17.7$ & $67.4 \pm 22.3$ & $56.8 \pm 24.3$ & $85.3 \pm 10.2$ \\
\hline$p$-value & 0.344 & 0.030 & 0.072 & 0.162 & 0.859 & 0.043 \\
\hline
\end{tabular}

Values are presented as mean \pm standard deviation.

CPCHILD: Caregiver Priorities and Child Health Index of Life with Disabilities, GMFCS: gross motor functional classification system. 
Kwon et al. Physical Activity in Cerebral Palsy Patients

Clinics in Orthopedic Surgery • Vol. 12, No. 1, $2020 \bullet$ www.ecios.org

long distances. However, given that accelerometers may also underestimate normally developed participants' PA arising from bicycle use and that patients classified as GMFCS level II or III made up less than half of the patients, errors on estimated PA could be tolerated.

For the validation of questionnaires assessing PA, the choice of an appropriate criterion measure is important. The gold standard for estimating energy expenditure in free-living humans is the doubly labelled water method, ${ }^{23)}$ but its cost has made it difficult to apply to field-based research. In addition, this method is unable to provide information about the level of intensity, duration, and frequency of PA. In the present study, data from an accelerometer were considered a criterion measure for concurrent validity analysis.

Time spent in PA at every level of intensity, steps, and the distance measured by an accelerometer in patients with CP were significantly lower than in normally developed participants. In contrast, the amount of time spent being sedentary was significantly higher in patients with CP. However, PA assessed by the IPAQ was significantly higher in patients than in normally developed participants, suggesting that patients with $\mathrm{CP}$ tended to exaggerate their participation in PA. Patients with CP have gait abnormalities caused by deformity, muscle weakness, sensory loss, pain, and impaired motor control spasticity, and they experience difficulties in independent movement. Thus, patients should make more effort than do normally developed participants to travel the same distance, and this might make them feel as if they had performed a strenuous exercise. Thus, the difference between PA assessed by questionnaires and by objective assessment tools might be more distinct in patients with CP, so careful attention must be given when interpreting PA data from questionnaires in this population.
In the PODCI, sports/physical activity, happiness, and global function decreased significantly with age in patients, while pain increased. This result is similar to that of previous studies, in which increasing age has been shown to be associated with lower levels of PA. ${ }^{24-26)}$ On the other hand, transfer/basic mobility, sports/physical function, and happiness increased significantly as the number of steps and distance travelled increased. It is noteworthy that happiness increased significantly as time spent being very active increased. These results highlight the need for patients with CP to be physically active, even if gait abnormalities cause movement limitation. They may experience difficulties in movement or be exhausted during PA; however, continuous movement will eventually make them physically active and be in emotionally satisfying state.

In conclusion, our results suggest that patients with $\mathrm{CP}$ have a lower level of PA than do normally developed participants and that patients tend to exaggerate their participation in PA in self-reported questionnaires. A key finding is that happiness and quality of life were associated with higher levels of PA, highlighting the need to encourage patients with CP to be physically active. Our results could serve as a basis for programs targeting $\mathrm{PA}$ in patients with CP.

\section{CONFLICT OF INTEREST}

No potential conflict of interest relevant to this article was reported.

\section{ACKNOWLEDGEMENTS}

We thank Byung Chae Cho, MD, Myung Ki Chung, MD, Gye Wang Lee, MD, and Sang Young Moon, MD for data collection.

\section{REFERENCES}

1. Bax M, Goldstein M, Rosenbaum P, et al. Proposed definition and classification of cerebral palsy, April 2005. Dev Med Child Neurol. 2005;47(8):571-6.

2. Hanna SE, Rosenbaum PL, Bartlett DJ, et al. Stability and decline in gross motor function among children and youth with cerebral palsy aged 2 to 21 years. Dev Med Child Neurol. 2009;51(4):295-302.

3. Caspersen CJ, Powell KE, Christenson GM. Physical activity, exercise, and physical fitness: definitions and distinctions for health-related research. Public Health Rep. 1985;100(2):12631.
4. Harris SS, Caspersen CJ, DeFriese GH, Estes EH Jr. Physical activity counseling for healthy adults as a primary preventive intervention in the clinical setting: report for the US Preventive Services Task Force. JAMA. 1989;261(24):358898.

5. Wrotniak BH, Epstein LH, Dorn JM, Jones KE, Kondilis VA. The relationship between motor proficiency and physical activity in children. Pediatrics. 2006;118(6):e1758-65.

6. Fowler EG, Kolobe TH, Damiano DL, et al. Promotion of physical fitness and prevention of secondary conditions for children with cerebral palsy: section on pediatrics research 
Kwon et al. Physical Activity in Cerebral Palsy Patients

Clinics in Orthopedic Surgery • Vol. 12, No. 1, $2020 \bullet$ www.ecios.org

summit proceedings. Phys Ther. 2007;87(11):1495-510.

7. Reilly JJ, Penpraze V, Hislop J, Davies G, Grant S, Paton JY. Objective measurement of physical activity and sedentary behaviour: review with new data. Arch Dis Child. 2008;93(7):614-9.

8. Bjornson KF, Belza B, Kartin D, Logsdon R, McLaughlin J, Thompson EA. The relationship of physical activity to health status and quality of life in cerebral palsy. Pediatr Phys Ther. 2008;20(3):247-53.

9. Buffart LM, Roebroeck ME, Rol M, Stam HJ, van den BergEmons RJ; Transition Research Group South-West Netherlands. Triad of physical activity, aerobic fitness and obesity in adolescents and young adults with myelomeningocele. J Rehabil Med. 2008;40(1):70-5.

10. Craig CL, Marshall AL, Sjostrom M, et al. International physical activity questionnaire: 12-country reliability and validity. Med Sci Sports Exerc. 2003;35(8):1381-95.

11. Hagstromer M, Oja P, Sjostrom M. The International Physical Activity Questionnaire (IPAQ): a study of concurrent and construct validity. Public Health Nutr. 2006;9(6):75562.

12. Daltroy LH, Liang MH, Fossel AH, Goldberg MJ. The POSNA pediatric musculoskeletal functional health questionnaire: report on reliability, validity, and sensitivity to change. Pediatric Outcomes Instrument Development Group. Pediatric Orthopaedic Society of North America. J Pediatr Orthop. 1998;18(5):561-71.

13. Narayanan UG, Fehlings D, Weir S, Knights S, Kiran S, Campbell K. Initial development and validation of the Caregiver Priorities and Child Health Index of Life with Disabilities (CPCHILD). Dev Med Child Neurol. 2006;48(10):80412.

14. Sung KH, Kwon SS, Narayanan UG, et al. Transcultural adaptation and validation of the Korean version of Caregiver Priorities \& Child Health Index of Life with Disabilities (CPCHILD). Disabil Rehabil. 2015;37(7):620-4.

15. Freedson PS, Miller K. Objective monitoring of physical activity using motion sensors and heart rate. Res Q Exerc Sport. 2000;71(2 Suppl):S21-9.
16. Schmidt MD, Freedson PS, Chasan-Taber L. Estimating physical activity using the CSA accelerometer and a physical activity log. Med Sci Sports Exerc. 2003;35(9):1605-11.

17. Sloane R, Snyder DC, Demark-Wahnefried W, Lobach D, Kraus WE. Comparing the 7-day physical activity recall with a triaxial accelerometer for measuring time in exercise. Med Sci Sports Exerc. 2009;41(6):1334-40.

18. Masse LC, Fuemmeler BF, Anderson CB, et al. Accelerometer data reduction: a comparison of four reduction algorithms on select outcome variables. Med Sci Sports Exerc. 2005;37(11 Suppl):S544-54.

19. Matthews CE, Ainsworth BE, Thompson RW, Bassett DR Jr. Sources of variance in daily physical activity levels as measured by an accelerometer. Med Sci Sports Exerc. 2002;34(8):1376-81.

20. Cuomo AV, Gamradt SC, Kim CO, et al. Health-related quality of life outcomes improve after multilevel surgery in ambulatory children with cerebral palsy. J Pediatr Orthop. 2007;27(6):653-7.

21. Lee KM, Chung CY, Park MS, et al. Level of improvement determined by PODCI is related to parental satisfaction after single-event multilevel surgery in children with cerebral palsy. J Pediatr Orthop. 2010;30(4):396-402.

22. Carlon S, Shields N, Yong K, Gilmore R, Sakzewski L, Boyd R. A systematic review of the psychometric properties of Quality of Life measures for school aged children with cerebral palsy. BMC Pediatr. 2010;10:81.

23. Schoeller DA. Measurement of energy expenditure in freeliving humans by using doubly labeled water. J Nutr. 1988;118(11):1278-89.

24. Maher CA, Williams MT, Olds T, Lane AE. Physical and sedentary activity in adolescents with cerebral palsy. Dev Med Child Neurol. 2007;49(6):450-7.

25. Pirpiris M, Graham HK. Uptime in children with cerebral palsy. J Pediatr Orthop. 2004;24(5):521-8.

26. Stevens SL, Holbrook EA, Fuller DK, Morgan DW. Influence of age on step activity patterns in children with cerebral palsy and typically developing children. Arch Phys Med Rehabil. 2010;91(12):1891-6. 